Article

\title{
Confinement of Masonry Columns with Natural Lime-Based Mortar Composite: An Experimental Investigation
}

\author{
Valerio Alecci ${ }^{1}$, Mario De Stefano ${ }^{1}$, Stefano Galassi ${ }^{1, * \mathbb{C}}$, Raymundo Magos ${ }^{2}$ and Gianfranco Stipo ${ }^{1}$ \\ 1 Department of Architecture, University of Florence, 50121 Florence, Italy; valerio.alecci@unifi.it (V.A.); \\ mario.destefano@unifi.it (M.D.S.); gianfranco.stipo@unifi.it (G.S.) \\ 2 School of Architecture, Anáhuac University, 77500 Cancun, Mexico; raymundo.magos@anahuac.mx \\ * Correspondence: stefano.galassi@unifi.it
}

Citation: Alecci, V.; De Stefano, M.; Galassi, S.; Magos, R.; Stipo, G. Confinement of Masonry Columns with Natural Lime-Based Mortar Composite: An Experimental Investigation. Sustainability 2021, 13, 13742. https://doi.org/10.3390/ su132413742

Academic Editor: Manuel Duarte Pinheiro

Received: 19 November 2021 Accepted: 10 December 2021 Published: 13 December 2021

Publisher's Note: MDPI stays neutral with regard to jurisdictional claims in published maps and institutional affiliations.

Copyright: (c) 2021 by the authors. Licensee MDPI, Basel, Switzerland. This article is an open access article distributed under the terms and conditions of the Creative Commons Attribution (CC BY) license (https:// creativecommons.org/licenses/by/ $4.0 /)$.

\begin{abstract}
The paper presents the results of an experimental campaign on the confinement of masonry square columns with fiber-reinforced lime mortar (FRLM) composites made of a natural lime-based matrix. The experimental results show the effectiveness of such a composite for increasing both strength and ductility performances of strengthened columns. Predictive formulas from the literature and from the Italian guidelines CNR-DT 215/2018 do not perfectly fit the experimental outcomes and do not confirm the strength increase of the confined columns. The reason can be attributed to the very low mechanical properties of the natural matrix used to form such a composite. Therefore, considering that the use of a natural and sustainable matrix fully compatible with the masonry substrate is a fundamental requirement for strengthening masonry columns of buildings belonging to architectural heritage, an additional future effort should be made by researchers involved in this field. In particular, for a reliable prediction of the strength of masonry columns confined with composites made of natural matrices, wider experimental campaigns are necessary to refine available formulas with respect to different substrates and component materials.
\end{abstract}

Keywords: masonry columns; FRCM composites; confinement; experimental campaign; analytical predictions

\section{Introduction}

Masonry buildings constitute a large part of world historical heritage. Particular attention has always been devoted to the study of their state of conservation and their response to seismic activity through in situ investigations as well as analytical-numerical models [1-4]. Historic masonry buildings are usually characterized by typical elements with both structural and decorative functions at the same time, such as arches, vaults and columns. In case of seismic events or with load increases, these masonry elements show extreme vulnerability [5,6]; this phenomenon is often fostered by the natural deterioration of the original material properties. These architectural elements enrich the masonry, helping to enhance its aesthetic and typological character. In this context, the neoclassical architectures-for example, the well-known buildings of Palladio-as well as the common and more recent masonry buildings that characterize European historic city centers (Figure 1) can be taken as an important reference in Europe.

In Latin America, all the 17th and 18th century rich post-Baroque buildings with large colonnades, vaults and domes and the wide aqueducts marking the areas surrounding many Spanish colonial towns, have now been declared UNESCO World Heritage Sites (Figure 2).

All these buildings need to be structurally updated through appropriate retrofitting interventions in order to be preserved and maintained for future generations.

In this ambit, an important topic is represented by the strengthening interventions on compressed masonry columns. 


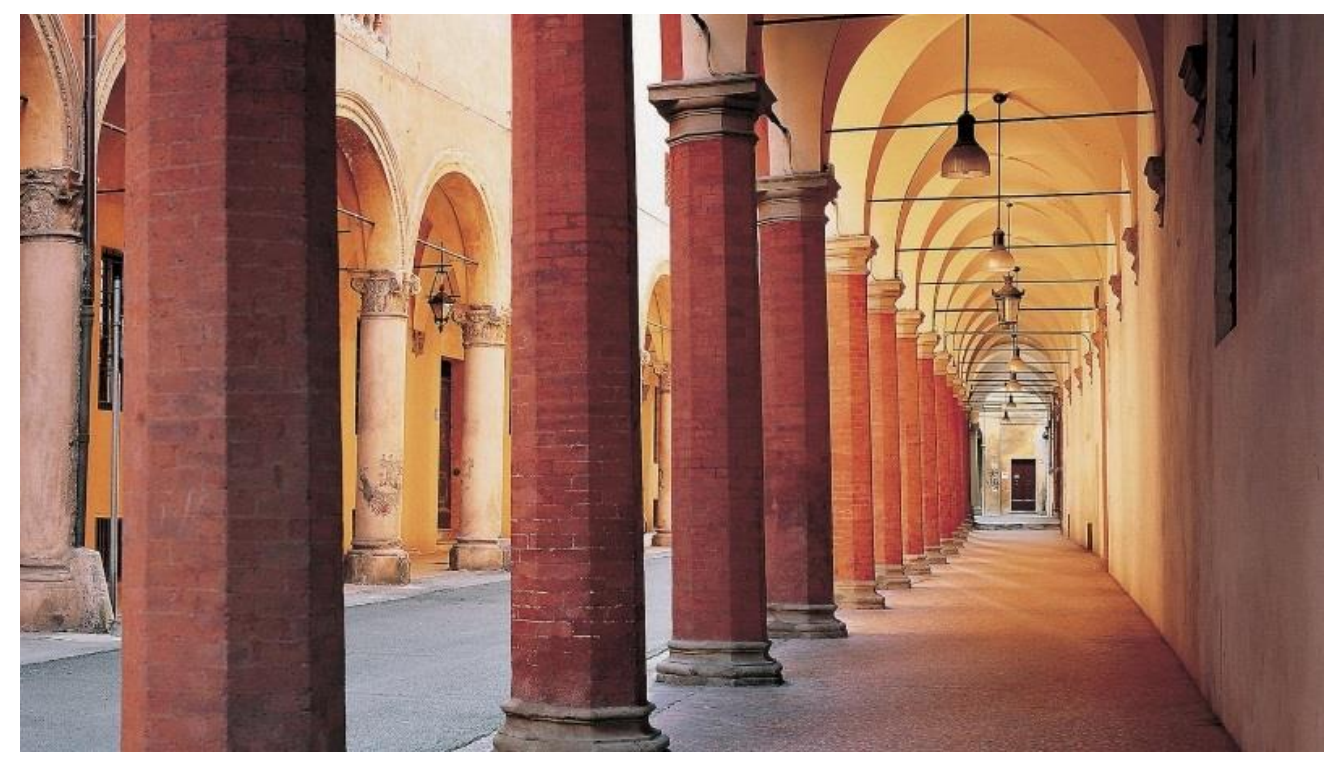

Figure 1. UNESCO World Heritage porticos in Bologna (Italy).

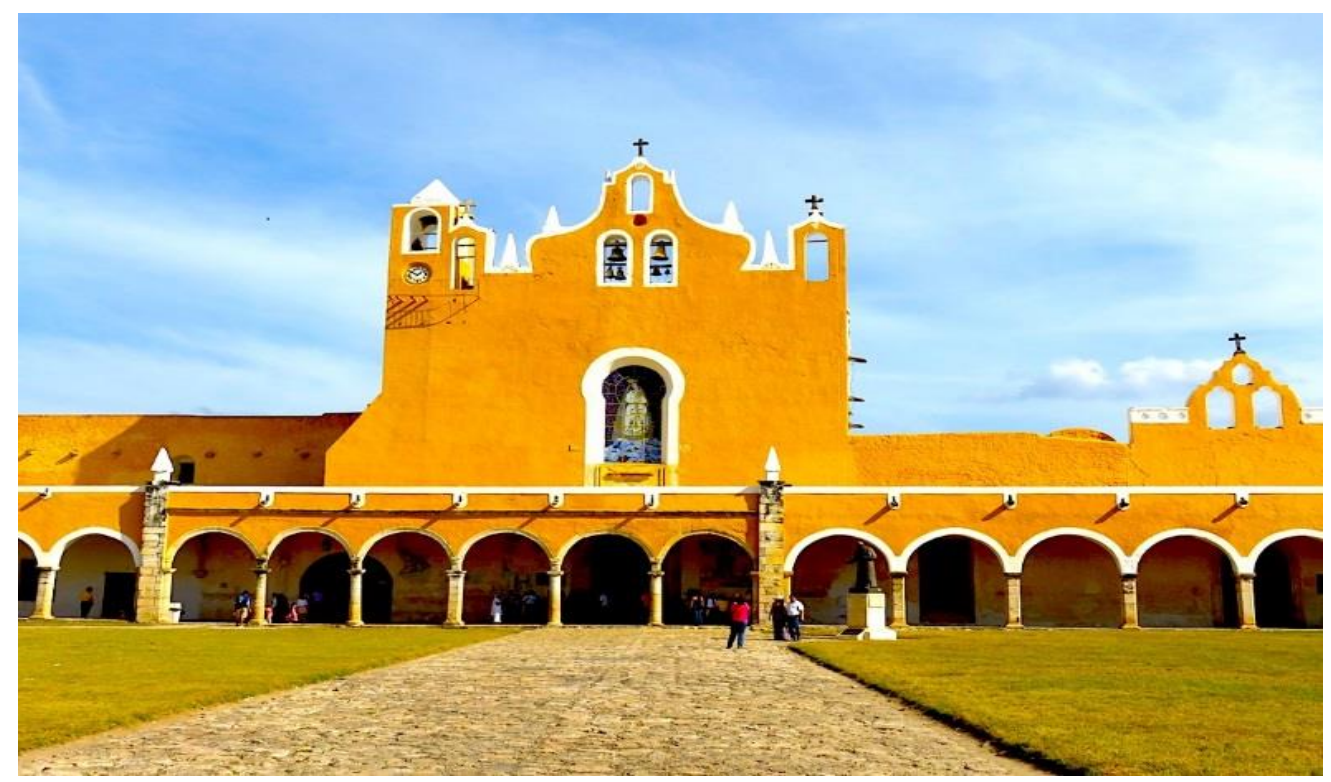

Figure 2. Historical masonry building in Merida/Cancun region (Mexico).

In order to strengthen such masonry members, traditional interventions include the use of iron bands or other metal devices to reduce transversal deformation. Sometimes metal hoops were applied and heated, followed by a cooling process in order to produce a pre-stress state, resulting in an active reinforcement. In the last two decades, fiberreinforced polymer (FRP) composites have been used as a passive intervention to increase the load-bearing capacity of both masonry and reinforced concrete columns. The crucial problem concerning the precise evaluation of the effective collaboration of the composite material wrap and the calculation of the maximum strength of reinforced columns were largely experimentally and analytically investigated [7-9].

At the same time, great attention was devoted to the definition of a theoretical model for the mechanical behaviour of FRP-reinforced columns. Campione and Miraglia [10] proposed a stress-strain relationship for a confined member, applying the formula proposed in Mander et al. [11] to predict the strength of a concrete compressed column confined by means of steel hoops. The form and coefficients of the equation were variously adapted in 
order to fit experimental results obtained for FRP-wrapped specimens and wide comparative studies on compressed members confined with FRP are available in the literature.

In the last decade, FRP composites have been progressively substituted by more compatible and sustainable composites made of a fabric embedded in a cement-based mortar (FRCM - fabric reinforced cementitious matrix). Today, FRCMs are usually preferred to FRP composites, especially for strengthening historical and monumental masonry constructions. Certain issues involving the bond performances of such composites are under experimental and numerical investigations $[12,13]$.

In fact, the scientific community raised the issue of the low physical-chemical compatibility of FRP composites with the masonry material, mainly in the case of historical and artistic buildings for which the sustainability of the intervention and the compatibility with the old substrate is strictly required. Concerning the strengthening of compressed masonry members, the use of FRCM composites is still in an early stage and only few experimental data and analytical studies are available in the literature [14-16]. In particular, load-carrying capacity, ductility properties and the failure mode of masonry columns strengthened with FRCM composites are still "open issues" that require a great effort of investigation from the scientific community.

Formulas in use to calculate the strength of masonry members confined with FRCM wraps are basically the same as those already used for FRP confinement, where the contribution of the mechanical properties of a mortar matrix is specifically considered. These formulas refer to an old expression used for confinement by means of steel reinforcement that dates back to 1929 and was presented by Richart et al. [17]. This expression was proposed as a result of an experimental campaign aimed at evaluating the strength of axially loaded concrete cylinders confined with a steel spiral [18]:

$$
\mathrm{f}_{\mathrm{cC}}=\mathrm{f}_{\mathrm{co}}+\mathrm{k}^{\prime} \mathrm{f}^{\prime}
$$

where $f_{c c}$ is the strength of the confined member, $f_{c o}$ is the strength of the unconfined member, $\mathrm{f}^{\prime}$ is the lateral uniform confining pressure and $\mathrm{k}^{\prime}$ is a coefficient that Richart proposed equal to 4.1 .

In subsequent years, other researchers used Richart's formulation for concrete columns reinforced with FRP wraps, but by reinterpreting the $\mathrm{f}^{\prime}$ parameter as the confinement pressure corresponding to the ultimate strength of the reinforcement.

After performing a wide experimental campaign, some researchers (Campione and Miraglia [10]) found that a value of $k^{\prime}$ equal to 4.1 in Equation (1) was not able to perfectly reproduce the strength of compressed elements wrapped with FRP; for this reason, they proposed a different value of the coefficient $k^{\prime}$.

Today, numerous formulations can be found in the literature, where different values of the $\mathrm{k}^{\prime}$ parameter are adopted by researchers in order to fit the outcomes of their experimental campaigns. It follows that the problem of the correct evaluation of the confinement effect produced by composite materials is currently partially unsolved and a further effort by the scientific community is necessary in order to provide more targeted and reliable formulas.

\section{Materials and Methods}

\subsection{The Effect of Masonry Column Confinement by Means of FRCM Composites}

In recent years, the strengthening of masonry columns using FRCM composites has been replacing the one based on FRP composites. The reasons depend on the greater compatibility between the inorganic matrices and the masonry substrate with respect to the epoxy matrices, as well as the greater breathability allowed to masonry, which reduces the formation of moisture spots and the complete reversibility of the strengthening intervention [19]. Recently in the literature [20], innovative techniques to make the confinement of masonry columns by FRP composites wrapping reversible, based on the interposition of separating films between the column and the jacket, have been proposed, but the problems related to low breathability persist. 
However, it is worth noting that the application of FRCM composites to masonry columns is very sensitive to the matrix type used to form the composite, both in terms of strength and ductility. In fact, it is well known that, for a chosen reinforcement textile, the use of a cement-based matrix, whose mechanical properties are higher than those of the masonry column, provides a very high strength increase, comparable to the one obtained using FRP composites. Nevertheless, the high increase of strength corresponds to a brittle behaviour of the masonry column, which fails due to the core disintegration that is kept together only by the strengthening wrap. Conversely, the use of a matrix characterized by mechanical properties not very different from those of the masonry member, such as a natural lime mortar, provides only a low strength increase but allows a much more ductile behaviour of the columns themselves. In fact, in this case, failure occurs with the spreading of vertical cracks while the masonry core preserves much more intact with a residual strength. Therefore, the choice of the matrix used to form the composite must be properly addressed for a targeted and correct strengthening intervention and this issue becomes more important in the case of interventions on historical and/or monumental buildings.

The possible use of composites assembled with different types of inorganic matrices has led researchers to formulate different analytical models to predict the strength of a confined column based on different coefficients calibrated to fit the results of laboratory tests, often performed by themselves. Currently, the many formulations available in the literature for FRCM-confined members are strongly affected by these coefficients and are basically derived from those previously proposed for FRP confined masonry columns. Two general expressions can be found in the literature: the first has been derived from the study of confined concrete columns and is reported in Equation (1); the second is reported in the following Equation (2):

$$
\mathrm{f}_{\mathrm{cc}}=\mathrm{f}_{\mathrm{co}}\left[1+\mathrm{k}^{\prime}\left(\frac{\mathrm{f}_{1}}{\mathrm{f}_{\mathrm{co}}}\right)^{\alpha}\right]
$$

The structure of Equation (1) expresses that the strength of a confined concrete column is given by the strength of the column devoid of the reinforcement plus a rate depending on the effect of the uniformly distributed confinement pressure (in the case of a circular member) increased by the coefficient $\mathrm{k}^{\prime}$ that incorporates the material and typology of the composite.

The structure of Equation (2) provides $\mathrm{k}^{\prime}$ with a different meaning, namely, the coefficient which increases the axial strength of the strengthened column. The structure of this equation is currently the one most preferred by the researchers involved in this field.

Some authors have even proposed an alternative formulation of Equation (2) to predict the ultimate strength of an FRCM-confined masonry column. This proposal is based on the reasoning that, if the confining composite material is a low volumetric fraction compared to the column size, its effect is negligible and the strengthening is ineffective, as reported in, e.g., [21]:

$$
\begin{gathered}
\mathrm{f}_{\mathrm{cc}}=\mathrm{f}_{\mathrm{co}} \text { if } \frac{\mathrm{f}_{\mathrm{l}}}{\mathrm{f}_{\mathrm{co}}} \leq 0.99 \\
\mathrm{f}_{\mathrm{cc}}=\mathrm{f}_{\mathrm{co}}\left[0.88+1.324\left(\frac{\mathrm{f}_{\mathrm{l}}}{\mathrm{f}_{\mathrm{co}}}\right)\right] \text { if } \frac{\mathrm{f}_{\mathrm{l}}}{\mathrm{f}_{\mathrm{co}}} \geq 0.99
\end{gathered}
$$

However, the main point of difference among the various formulations of Equation (2) proposed by numerous authors is the value assigned to the coefficient $k^{\prime}$. Some authors propose constant values for $\mathrm{k}^{\prime}$, for instance, Murgo and Mazzotti [15], who propose that $\mathrm{k}^{\prime}=1.53$. Other authors, such as Cascardi et al. [16], propose a coefficient $\mathrm{k}^{\prime}$ as a function of the characteristic compression strength $\mathrm{f}_{\text {mat }}$ of the composite matrix, as follows:

$$
\mathrm{f}_{\mathrm{cc}}=\mathrm{f}_{\mathrm{co}}\left[1+\mathrm{k}^{\prime}\left(\frac{\mathrm{f}_{\mathrm{l}}}{\mathrm{f}_{\mathrm{co}}}\right)^{0.5}\right] \text { where } \mathrm{k}^{\prime}=6 \rho_{\text {mat }} \frac{\mathrm{f}_{\text {mat }}}{\mathrm{f}_{\mathrm{co}}}, \rho_{\text {mat }}=\frac{4 \mathrm{t}_{\text {mat }}}{\mathrm{D}}
$$

where $\mathrm{D}$ indicates the diagonal of the rectangular section or the diameter of the circular section of the column. 
Balsamo et al. (Equation (5)) [22] and the Italian guidelines CNR-DT 215/2018 [21] (Equation (6)) compute the coefficient $k^{\prime}$ based on the density gm of masonry:

$$
\begin{gathered}
\mathrm{f}_{\mathrm{cc}}=\mathrm{f}_{\mathrm{co}}\left[1+\mathrm{k}^{\prime}\left(\frac{\mathrm{f}_{\mathrm{l}}}{\mathrm{f}_{\mathrm{co}}}\right)\right] \text { where } \mathrm{k}^{\prime}=\left(\frac{\mathrm{g}_{\mathrm{m}}}{1000}\right)^{0.662} \\
\mathrm{f}_{\mathrm{cc}}=\mathrm{f}_{\mathrm{co}}\left[1+\mathrm{k}^{\prime}\left(\frac{\mathrm{f}_{\mathrm{l}}}{\mathrm{f}_{\mathrm{co}}}\right)^{0.5}\right] \text { where } \mathrm{k}^{\prime}=\left(\frac{\mathrm{g}_{\mathrm{m}}}{1000}\right)
\end{gathered}
$$

Currently, the reference code for confining intervention of masonry columns using a FRCM wrapping is provided by the Italian guidelines CNR-DT 215/2018 [23]. These guidelines recommend confining a masonry column using a continuous wrapping made of composite material with fibers aligned orthogonally to the geometrical axis of the column and embedded within an inorganic matrix in such a way as to counteract the transversal expansion.

According to these guidelines, the ultimate axial strength $\mathrm{f}_{\text {mcd }}$ of the confined column is given by Equation (2), which is rewritten as in Equation (7):

$$
\mathrm{f}_{\mathrm{mcd}}=\mathrm{f}_{\mathrm{md}}\left[1+\mathrm{k}^{\prime}\left(\frac{\mathrm{f}_{\mathrm{l}, \mathrm{eff}}}{\mathrm{f}_{\mathrm{md}}}\right)^{\alpha_{1}}\right]
$$

where $f_{m c d}$ is the axial compressive strength of the confined column, $f_{m d}$ that of the unconfined column, $\mathrm{f}_{\mathrm{l} \text {,eff }}$ is the effective lateral confining pressure, $\mathrm{k}^{\prime}$ is the coefficient of strength increase and $\alpha_{1}$ is an exponent which is set equal to 0.5 if experimental data are not available.

The coefficient $\mathrm{k}^{\prime}$ is computed as a function of the density of the composite matrix, according to Equation (8):

$$
\mathrm{k}^{\prime}=\alpha_{2}\left(\frac{\mathrm{g}_{\mathrm{m}}}{1000}\right)^{\alpha_{3}}
$$

where $\alpha_{2}$ and $\alpha_{3}$ are set equal to 1 in the absence of experimental data which can justify the adoption of different values.

Since only in the case of a circular column the lateral confining pressure $f_{l}$ acts uniformly along the cross-section and is entirely effective to counteract the lateral expansion, in the case of a square or rectangular column only a rate of it can be considered as actually effective because the stress distribution inside the cross-section of the column follows the so called "arch effect". According to this theory, there is a stress concentration at the corners of the cross-section while at the mid-sides the section the stress is practically zero. For this reason, the edges of the cross-section are recommended to be rounded and the effective lateral confining pressure is introduced in Equation (7) in the place of $f_{l}$ and computed according to Equation (9):

$$
\mathrm{f}_{1, \text { eff }}=\mathrm{k}_{\mathrm{H}} \mathrm{f}_{1}
$$

Coefficient $\mathrm{k}_{\mathrm{H}}$ is denoted as the coefficient of horizontal efficiency and depends exactly on the shape of the cross-section of the column. In the case of a circular column, $\mathrm{k}_{\mathrm{H}}=1$, while in the case of a rectangular column of sides B and $\mathrm{H}$ and diagonal $\mathrm{D}$ it is obtained through Equation (10):

$$
\mathrm{k}_{\mathrm{H}}=1-\frac{\mathrm{B}^{2}+\mathrm{H}^{2}}{3 \mathrm{BH}}
$$

Finally, to compute the lateral confining pressure, the Italian guidelines provide Equation (11):

$$
\mathrm{f}_{1}=\frac{2 \mathrm{n}_{\mathrm{f}} \mathrm{t}_{\mathrm{f}} \mathrm{E}_{\mathrm{f}} \epsilon_{\mathrm{ud}, \mathrm{rid}}}{\mathrm{D}}
$$

where $n_{f}$ and $t_{f}$ are the number of layers and the equivalent thickness of the reinforcement, respectively, and $\epsilon_{\mathrm{ud}, \text { rid }}$ is the strain of the FRCM composite, computed as follows: 


$$
\epsilon_{\mathrm{ud}, \text { rid }}=\min \left(\mathrm{k}_{\mathrm{mat}} \cdot \eta_{\mathrm{a}} \cdot \frac{\epsilon_{\mathrm{uf}}}{\gamma_{\mathrm{m}}} ; 0.004\right)
$$

0.004 being the conventional value of the strain for which the masonry core of the column is considered to be disintegrated and is held together only by the wrapping textile; $\eta_{a}$ is the environmental conversion factor set equal to 1 and $\gamma_{\mathrm{m}}$ is the partial material safety factor set equal to 1.5 for ultimate limit states. To compute the coefficient $k_{\text {mat }}$ in Equation (12), the following formulas are provided:

$$
\begin{gathered}
\mathrm{k}_{\mathrm{mat}}=\alpha_{4} \cdot\left(\rho_{\mathrm{mat}} \cdot \frac{\mathrm{f}_{\mathrm{c}, \mathrm{mat}}}{\mathrm{f}_{\mathrm{md}}}\right)^{2} \\
\rho_{\text {mat }}=\frac{4 \mathrm{t}_{\mathrm{mat}}}{\mathrm{D}}
\end{gathered}
$$

where $\alpha_{4}$ is set equal to 1.81 if experimental data are not available, $\mathrm{f}_{\mathrm{c}, \text { mat }}$ is the characteristic compression strength of the matrix and $t_{\text {mat }}$ the overall thickness of the composite.

\subsection{Laboratory Tests}

An experimental campaign was carried out at the Materials and Structures Testing Laboratory of the University of Florence. The experimental program was organized into two main phases. The first phase concerned the mechanical characterization of all the constituent materials (of the masonry specimens and of the composite material). In the second phase, six square columns, $250 \times 250 \times 500 \mathrm{~mm}^{3}$ in size, with a full-scale cross-section, were built assembling bricks and cement-lime mortar. After 28 days of curing under constant levels of temperature and humidity, three of the six columns were strengthened with a composite material made of a natural lime-based matrix and a balanced polyparaphenylenebenzobisoxazole $(\mathrm{PBO})$ mesh. All the columns were then subjected to a uniaxial compression test to evaluate the effectiveness of the confinement provided by the fiber-reinforced lime mortar composite.

\subsubsection{Mechanical Characterization of Masonry: Bricks and Cement-Lime Mortar Joints}

Bricks and cement-lime mortar were mechanically characterized according to the standard UNI EN 772-1:2015 [24] and UNI EN 1015-11 [25], respectively, and the average values of corresponding results are reported in Table 1 . The bricks used for the construction of the columns, $250 \times 120 \times 55 \mathrm{~mm}^{3}$ in size, were provided by the San Marco Terreal Company. The bricks were tested under three-point bending tests, while uniaxial compressive tests were performed on cubic specimens of $50 \times 50 \times 50 \mathrm{~mm}^{3}$ in size, obtained by cutting the original bricks. Specimens of the cement-lime mortar used for the masonry assemblage, $160 \times 40 \times 40 \mathrm{~mm}^{3}$ in size, were subjected to three-point bending tests, then compressive tests were performed on the stumps obtained after the bending test failure.

Table 1. Result of three-point bending tests and uniaxial compression tests on bricks and cement-lime mortar specimens.

\begin{tabular}{ccc}
\hline Material & $\begin{array}{c}\text { Compression Strength (MPa) } \\
\text { (Standard Deviation; CoV) }\end{array}$ & $\begin{array}{c}\text { Flexural Tensile Strength (MPa) } \\
\text { (Standard Deviation; CoV) }\end{array}$ \\
\hline \multirow{2}{*}{ Brick } & 17.10 & 5.60 \\
& $(0.84 ; 0.05)$ & $(0.58 ; 0.10)$ \\
Cement-lime mortar joint & 2.92 & 0.44 \\
& $(0.18 ; 0.06)$ & $(0.07 ; 0.16)$ \\
\hline
\end{tabular}

\subsubsection{Mechanical Characterization of FRLM Composites}

The composite material was obtained by embedding a PBO fabric in a natural lime mortar matrix prepared in the laboratory. 
The lime-based mortar was mixed according to the following proportions: one part lime, one part water, three parts river sand. The mortar is fully natural, and it was mixed without any other additives. First, the mortar specimens, $160 \times 40 \times 40 \mathrm{~mm}^{3}$ in size, were subjected to three-point bending tests and then the two stumps produced by the rupture of each prism were subjected to uniaxial compression tests. The results of the tests are shown in Table 2. It is important to note that the strength of the natural lime mortar was lower than $1 \mathrm{MPa}$.

Table 2. Result of three-point bending tests and uniaxial compression tests on lime-based mortar.

\begin{tabular}{ccc}
\hline \multirow{2}{*}{ Material } & $\begin{array}{c}\text { Compression Strength } \mathbf{f}_{c, \text { mat }} \\
(\mathbf{M P a})\end{array}$ & $\begin{array}{c}\text { Flexural Tensile Strength } \mathbf{f}_{\mathbf{t}} \\
\mathbf{( M P a )}\end{array}$ \\
\cline { 2 - 3 } & (Standard Deviation; CoV) & (Standard Deviation; CoV) \\
\hline Lime-based mortar & 0.79 & 0.64 \\
$(0.12 ; 0.15)$ & $(0.02 ; 0.03)$ \\
\hline
\end{tabular}

The PBO fabric, with the equivalent thickness of $0.014 \mathrm{~mm}$, provided by the manufacturer, is a bidirectional net with a weight of $22 \mathrm{~g} / \mathrm{mm}^{3}$ both in the warp and in the weft direction. The weaving of the PBO mesh provides sufficient spaces for the passage of the inorganic matrix (Figure 3) and, therefore, it improves the adhesion between the matrix and the PBO fabric. PBO specimens were made of five yarns in the longitudinal direction and subject to tensile tests. The results of the tensile tests are summarized in the stress-strain diagram plotted in Figure 4 and are also reported in Table 3, where they are compared with data provided by the manufacturer. A discrepancy between results obtained experimentally and from datasheets can be observed, probably due to the number of specimens tested, the test rate and the influence of the gripping system; in the analytical study proposed in this investigation the experimental results will be adopted.

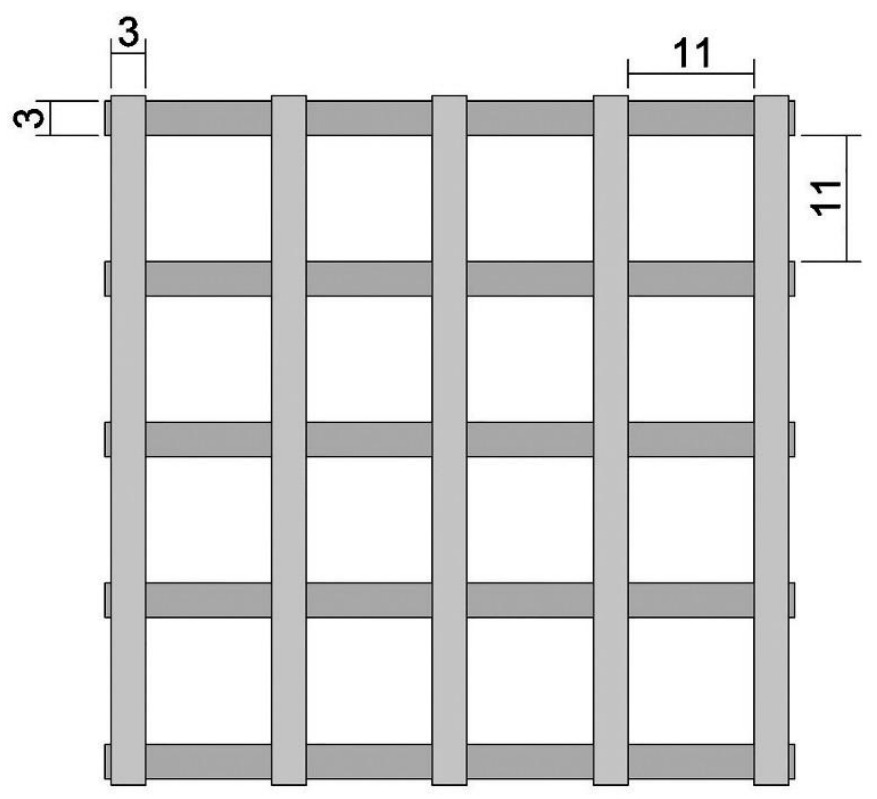

Figure 3. PBO-fiber textile, geometry (mm). 


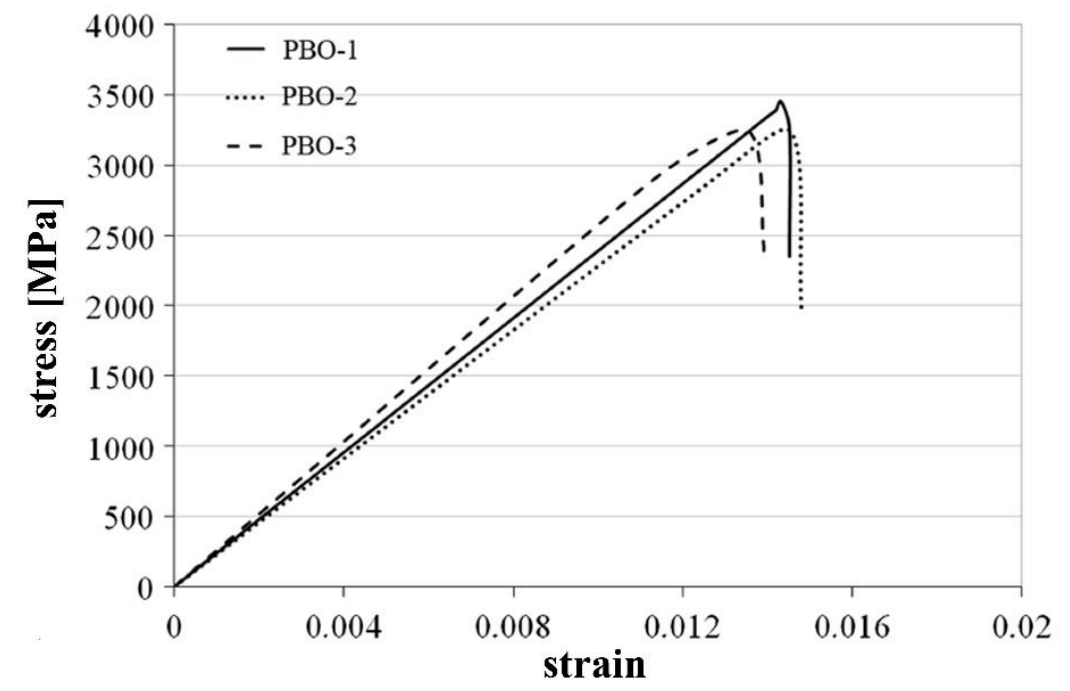

Figure 4. Stress-strain diagram of the tensile test of PBO-fiber textile.

Table 3. Result of tensile test on PBO mesh.

\begin{tabular}{cccc}
\hline Material & $\sigma_{\mathbf{t}}$ & $\mathbf{E}_{\mathbf{f}}$ & $\varepsilon_{\mathbf{u f}}$ \\
\hline & $(\mathrm{MPa})$ & $(\mathrm{MPa})$ & \\
\hline \multirow{2}{*}{$\mathrm{PBO}$} & $3300^{*}$ & $270,000^{*}$ & $0.0149^{*}$ \\
& $5800^{* *}$ & $282,000^{* *}$ & $0.025^{* *}$ \\
\hline
\end{tabular}

* Experimental value; ${ }^{* *}$ Data from manufacturer datasheet.

The stress-strain diagram (Figure 4) provided by the tensile test shows a rather linear elastic behavior until the peak load was attained and brittle failure occurred.

Finally, it is worth noting that the efficacy of FRLM reinforcement depends on the adhesion between the fabric and the matrix. Therefore, to assess this aspect, tensile tests were carried out on three coupons consisting of a matrix sheet, with dimensions of $500 \times 65 \times 10 \mathrm{~mm}^{3}$, in which the PBO mesh was embedded (Figure 5).
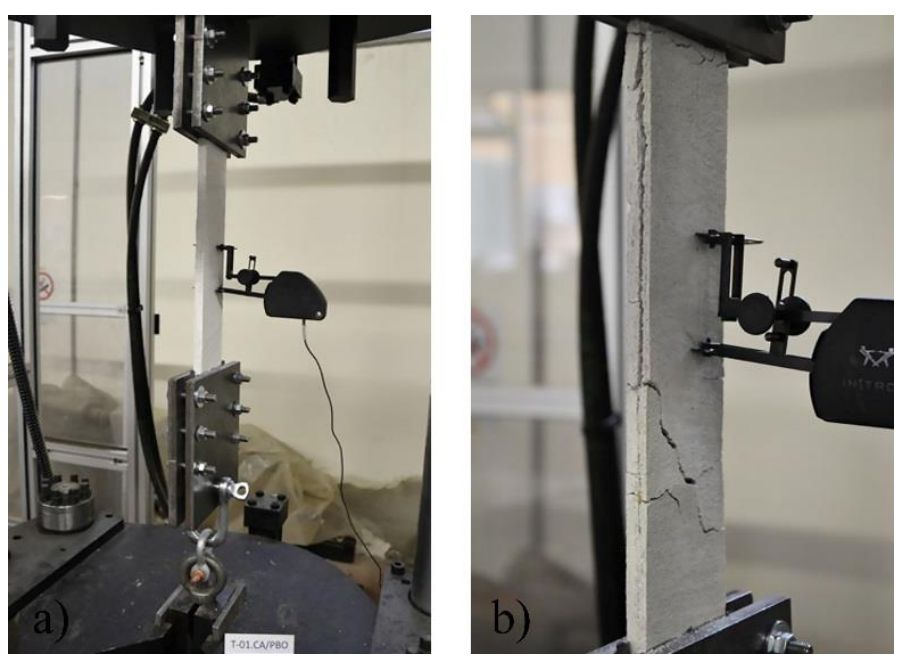

Figure 5. Tensile test on the PBO-FRLM coupon: (a) detail of the testing machine; (b) test execution.

Tests were performed using a specifically designed gripping system (Figure 5a) consisting of two couples of steel-bolted plates bracing the specimen, with the aim of preventing slippage phenomena, and a couple of steel plates connected to the clamps of the testing machine. The connections are constituted by a lower D-shackle and two shank hooks 
welded to the steel plates, as shown in Figure 5a, in order to provide a rotational degree of freedom in the plane of the specimen, eliminating any parasitic bending moment.

The tensile strength was calculated as the ratio between the peak load $\mathrm{F}_{\max }$ and the area of the cross-section of the fabric, which was obtained by multiplying the width of the specimen by the equivalent thickness of the fabric itself. Test results are reported in Table 4 and if Figure 6.

Table 4. FRLM Composite test results.

\begin{tabular}{ccccc}
\hline Specimen & $\mathbf{F}_{\max }(\mathbf{N})$ & $\mathbf{d}_{\max }$ & $\boldsymbol{\sigma}(\mathbf{M P a})$ & $\varepsilon_{\max }$ \\
\hline T-01.CA/PBO & 835.83 & 2.89 & 918.49 & 0.012 \\
T-02.CA/PBO & 800.19 & 2.83 & 879.33 & 0.011 \\
T-03.CA/PBO & 826.02 & 2.85 & 907.71 & 0.010 \\
\hline
\end{tabular}

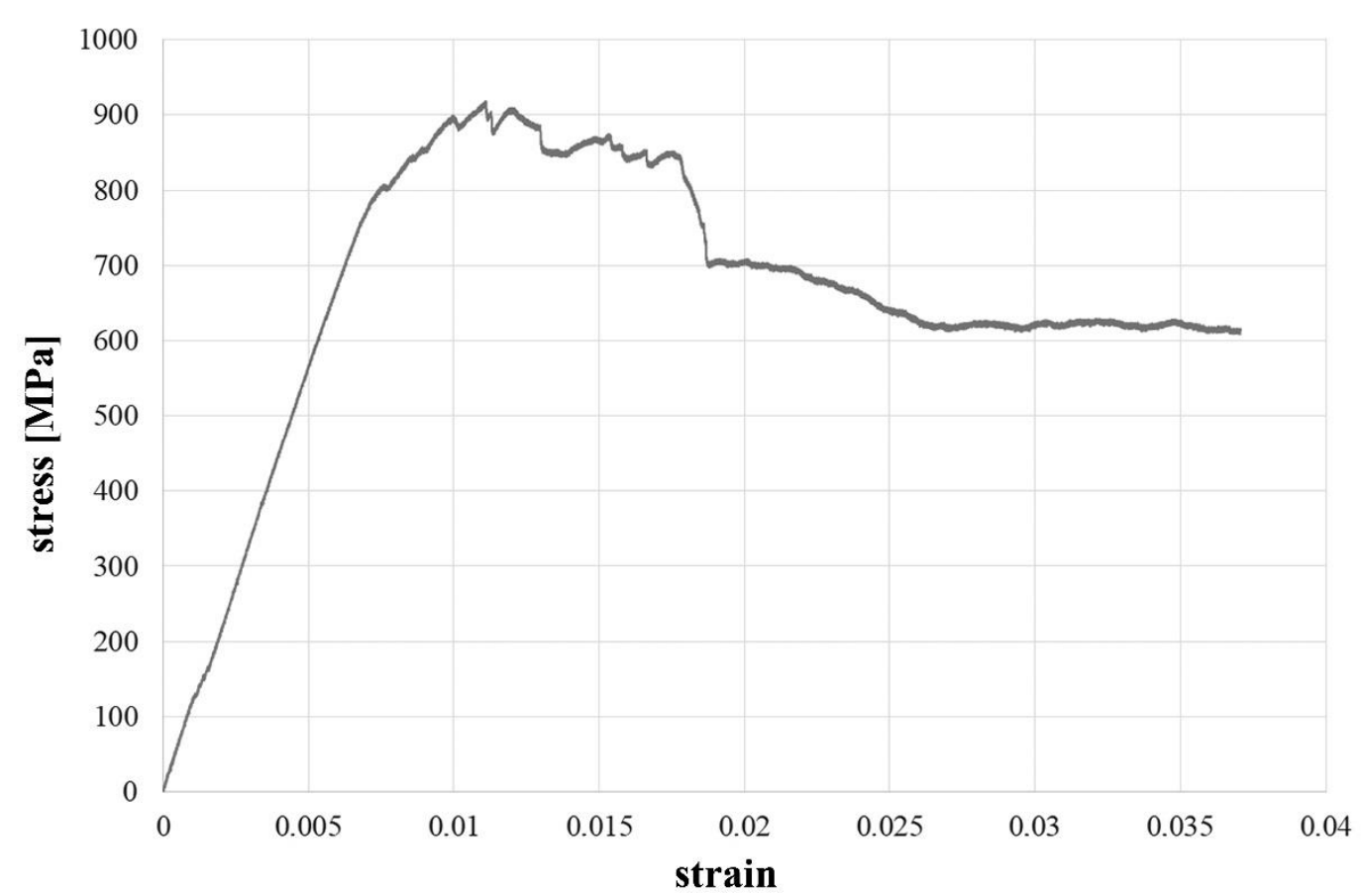

Figure 6. Stress-strain diagram provided by the tensile tests of the FRLM composites.

Figure 6 shows the constitutive law of the FRLM composite, provided by the tensile test, according to which three main branches can be recognized. In the first branch the specimen is not cracked and exhibits pseudo-linear elastic behavior; in the second ascending branch the composite experiences widespread cracks and in the third one the matrix is completely cracked and the fabric slides within it due to the loss of adhesion.

Table 4 shows that the tensile strength of FRCM was lower than that of the dry fabric. In the authors' opinion, this could be due to the presence and type of matrix and, above all, to the gripping system used to link the specimen to the testing machine, as has been reported in the literature [26]. This phenomenon is not new and it is much discussed in the literature [27-31].

\subsubsection{Mechanical Characterization of Columns}

After the mechanical characterization of the constituent materials of both the masonry columns and the FRLM composite, six masonry columns with a full-scale cross-section were assembled as shown in Figure 7a. Each specimen is a square column built with 16 bricks, arranged in pairs in a staggered way in a sequence of eight rows and $10 \mathrm{~mm}$ thick mortar joints. After 28 days of curing, according to the CNR-DT 215/2018 [23], the corners of the three columns to be strengthened with FRLM composite were rounded in 
order to avoid localized stress concentrations at the edges and premature failure. Because the higher the radius of curvature of the corners the higher the load-bearing capacity of the column [32], and since the radius is recommended to be at least $20 \mathrm{~mm}$ in the abovementioned standard [23], in the specific case a radius of curvature of $30 \mathrm{~mm}$ was adopted to round off the edges of the specimens (Figure $7 \mathrm{~b}$ ).

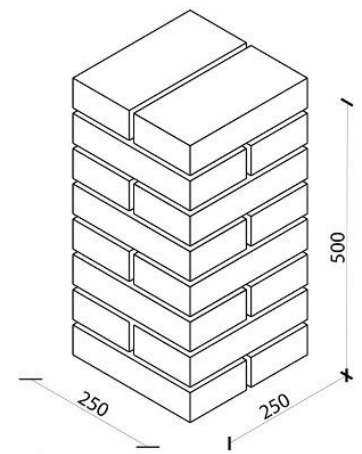

a)

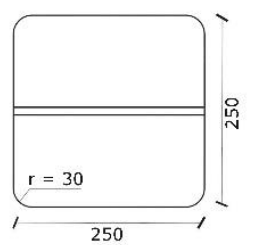

b)

Figure 7. (a) Masonry columns to be tested. (b) Corner rounding of $30 \mathrm{~mm}$.

Then, column faces were cleaned and smoothed in order to eliminate surface defects and wetted in order to prevent the specimens from absorbing the mortar mixing water during the application of the composite material. Subsequently, a first layer of matrix was applied on the four peripheral sides of the columns with a thickness of about $5 \mathrm{~mm}$ (Figure 8a). Once the first layer was completed, the PBO mesh was quickly applied to the matrix around the column with an overlapping length of the net equal to $300 \mathrm{~mm}$, as recommended in [23]. Finally, a second $5 \mathrm{~mm}$ thick layer of matrix was applied to cover the textile (Figure $8 \mathrm{~b}$ ). In order to avoid a direct load on the composite wrap during the test, a gap of $20 \mathrm{~mm}$ was considered between the top of the column and the beginning of the wrap itself.

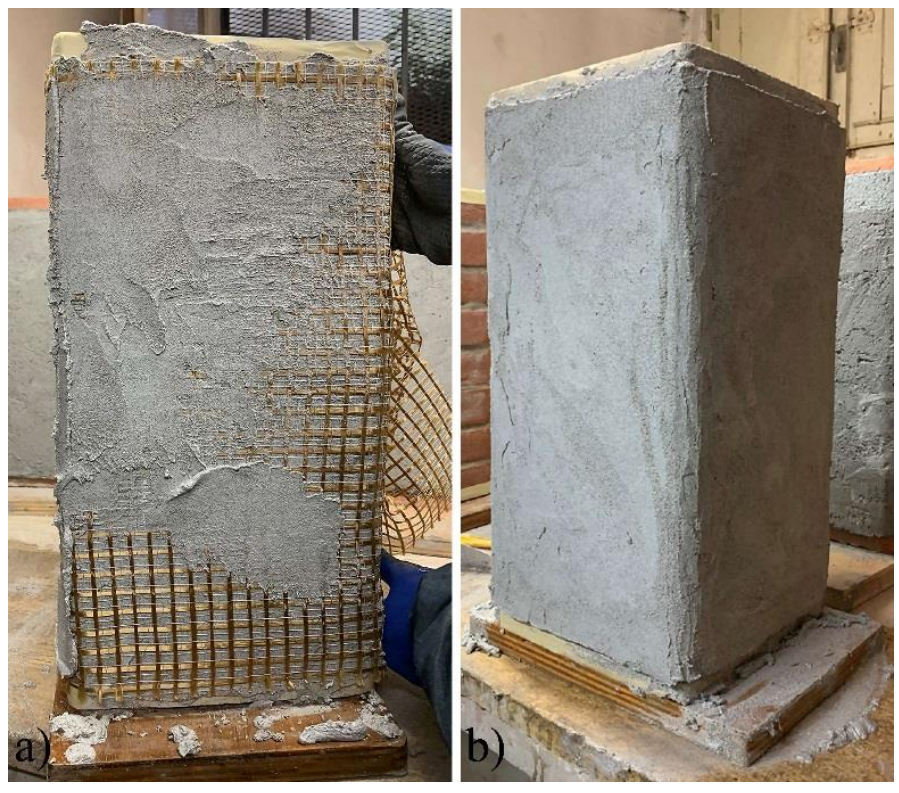

Figure 8. Columns strengthened with the FRLM composite. (a) Execution of the first layer of matrix and positioning of the textile. (b) Specimen completed with the second layer of matrix.

Each column was placed under a $3000 \mathrm{kN}$ universal press and subjected to a uniaxial compression test. Tests were performed under displacement control with a rate of 
$0.4 \mathrm{~mm} / \mathrm{min}$. Displacements were acquired through two displacement transducers placed at the top of the specimens.

\section{Results}

The results of the uniaxial compression tests on the masonry columns, both unconfined and confined with the FRLM composite, are summarized in Table 5, where the peak load $\left(F_{\max }\right)$, the ultimate compression stress $(\sigma)$ and the ductility factor $(\mu \mathrm{u})$, computed as the ratio between the displacement corresponding to the ultimate load (conventionally assumed to be $80 \%$ of the peak load) and the displacement measured at the end of the elastic field [33], are reported.

Table 5. Results of uniaxial compression tests on the unstrengthened columns (NR-C1, NR-C2, NR-C3) and on the strengthened ones (LR-C1, LR-C2, LR-C3).

\begin{tabular}{cccc}
\hline \multirow{2}{*}{ ID Specimen } & $\mathbf{F}_{\mathbf{m a x}}$ & $\boldsymbol{\sigma}_{\mathbf{C}}$ & $\boldsymbol{\mu u}$ \\
\cline { 2 - 4 } & $\mathbf{( k N )}$ & $\mathbf{( M P a )}$ & \\
\hline NR-C1 & 556.35 & 8.90 & 1.02 \\
NR-C2 & 529.65 & 8.47 & 1.14 \\
NR-C3 & 512.04 & 8.19 & 1.15 \\
\hline Average & 532.68 & 8.52 & 1.10 \\
\hline LR-C1 & 643.75 & 10.30 & 1.86 \\
LR-C2 & 583.36 & 9.33 & 2.11 \\
LR-C3 & 706.34 & 11.30 & 1.52 \\
\hline Average & 594.43 & 10.31 & 1.83 \\
\hline
\end{tabular}

The three unstrengthened columns, labelled NR-C1, NR-C2, NR-C3 in Table 5, showed very similar behaviour during the tests and the same type of failure. The specimens highlighted vertical cracks triggered in the upper or lower sides and then quickly expanded up to the middle of the specimens (Figure 9). Load-displacement diagrams showed linear elastic behaviour up to the peak load without a softening phase, while a brittle failure occurred (Figure 10).
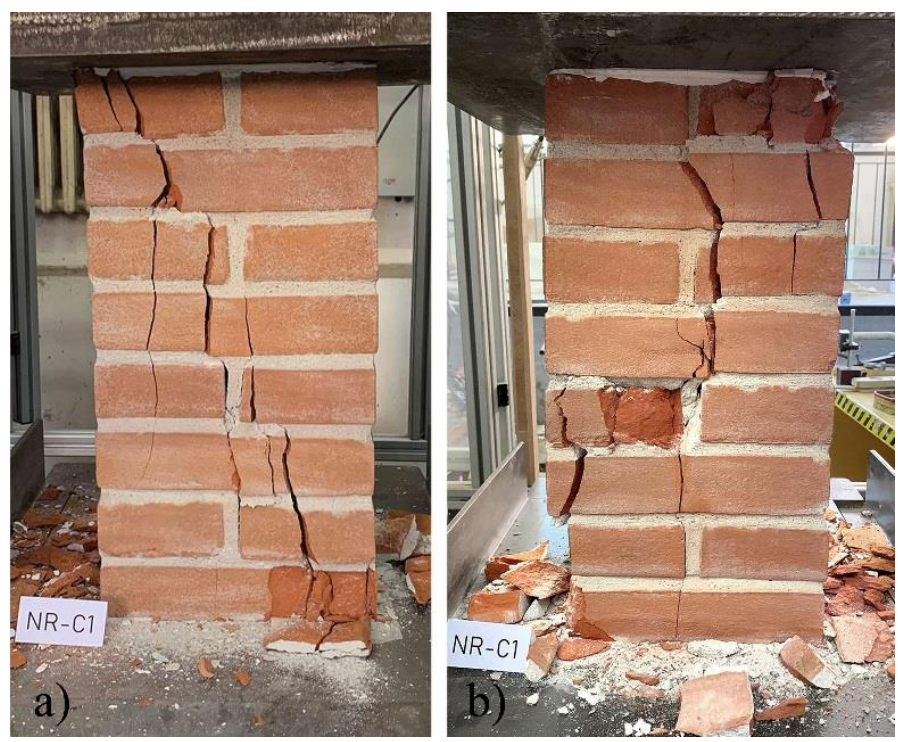

Figure 9. Reference failure mode of unreinforced masonry columns (NR-C1 specimen): (a) front and (b) back sides. 


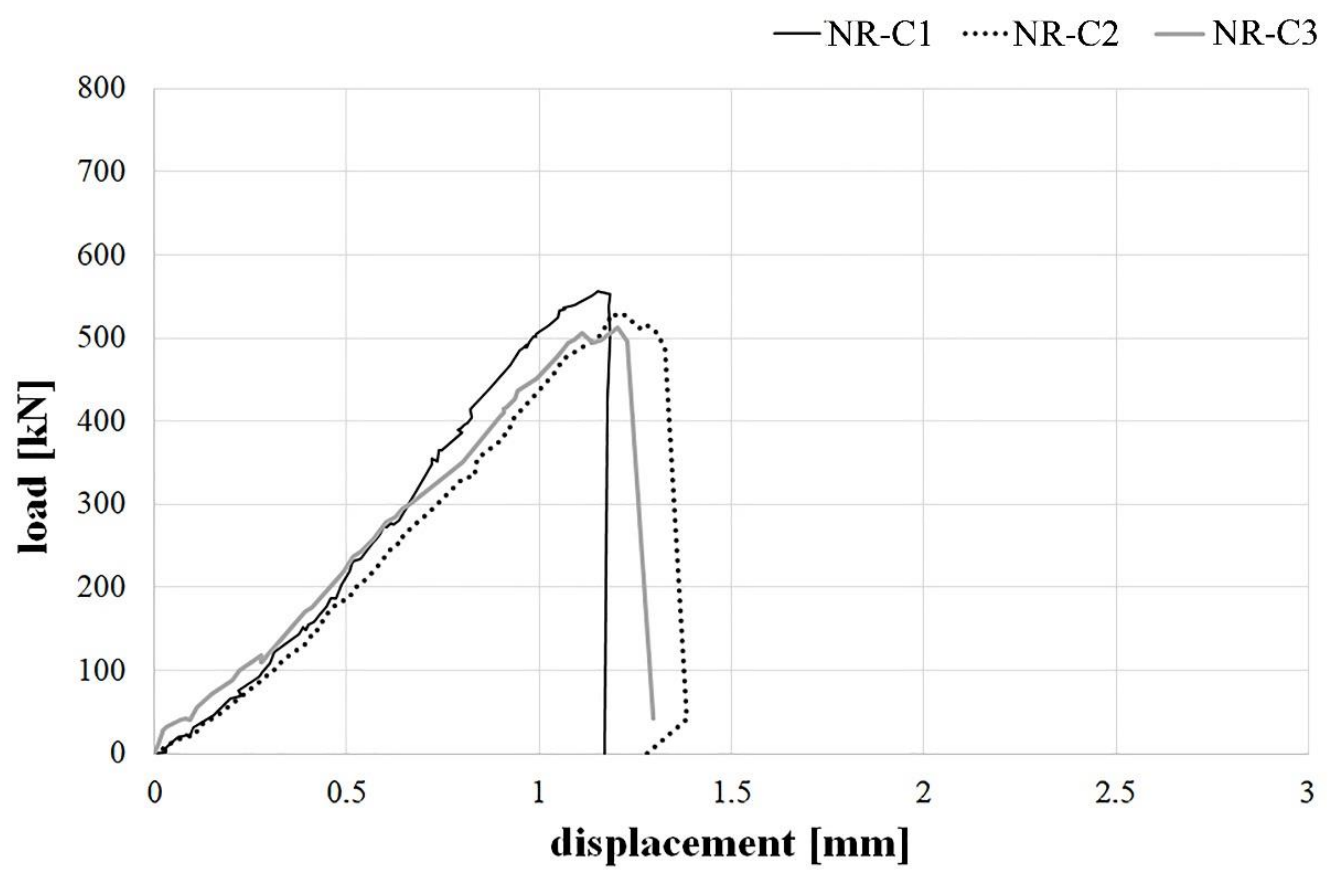

Figure 10. Load-displacement diagram provided by the uniaxial compression tests of the unstrengthened masonry columns.

The masonry columns strengthened with the FRLM composite were tested according to the same procedure that was followed for the unstrengthened ones. A first crack occurred from the top towards the middle of the specimen, and, as the load increased, the surface of the lime matrix highlighted many cracks due to the beginning of the sliding between the fabric and the matrix. A first detachment occurred between the outermost layer of the matrix and the fabric, then the sliding continued up to the complete detachment from the masonry substrate due to the failure of the column inner core. At the end of the test, the fabric remained mostly undamaged even if completely detached by the matrix layers (Figure 11a) while the inner core of the specimen appeared largely damaged (Figure 11b).
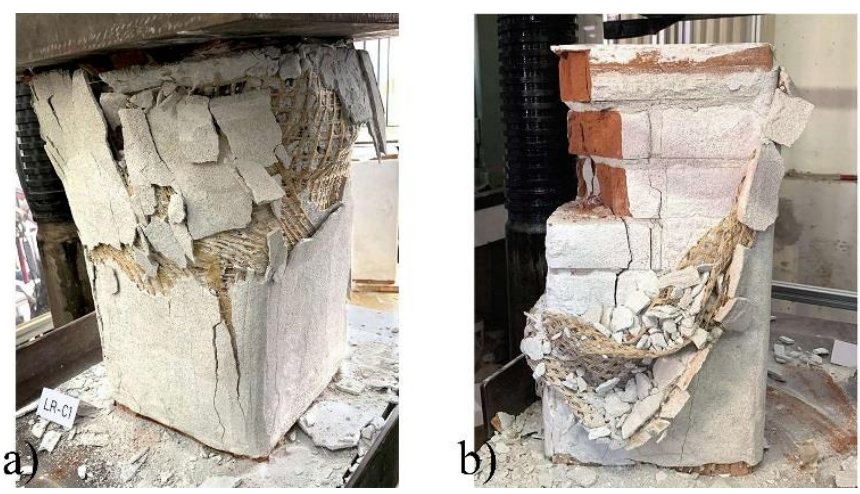

Figure 11. Reference failure mode of the strengthened specimens (LR-C1): (a) reinforcement and (b) inner masonry condition.

Load-displacement diagrams were compared to the curve of the NR-C2 unstrengthened column, taken as a reference (Figure 12). The comparison highlights that the behaviour of the unstengthened and the strengthened columns is rather similar in the ascending branch, confirming that wrap scarcely collaborates in this phase, becoming effective only after that the value of the maximum load of the unstrengthened column was reached. A large "post-elastic" branch can be appreciated corresponding to the phase of sliding between the fabric and the surrounding matrix. The FRLM wrap was demonstrated to 
be able to provide an increase in load-bearing capacity and ductility. As is well known, columns typically show a brittle behaviour, and an increase of ductility is largely desired in seismic areas.

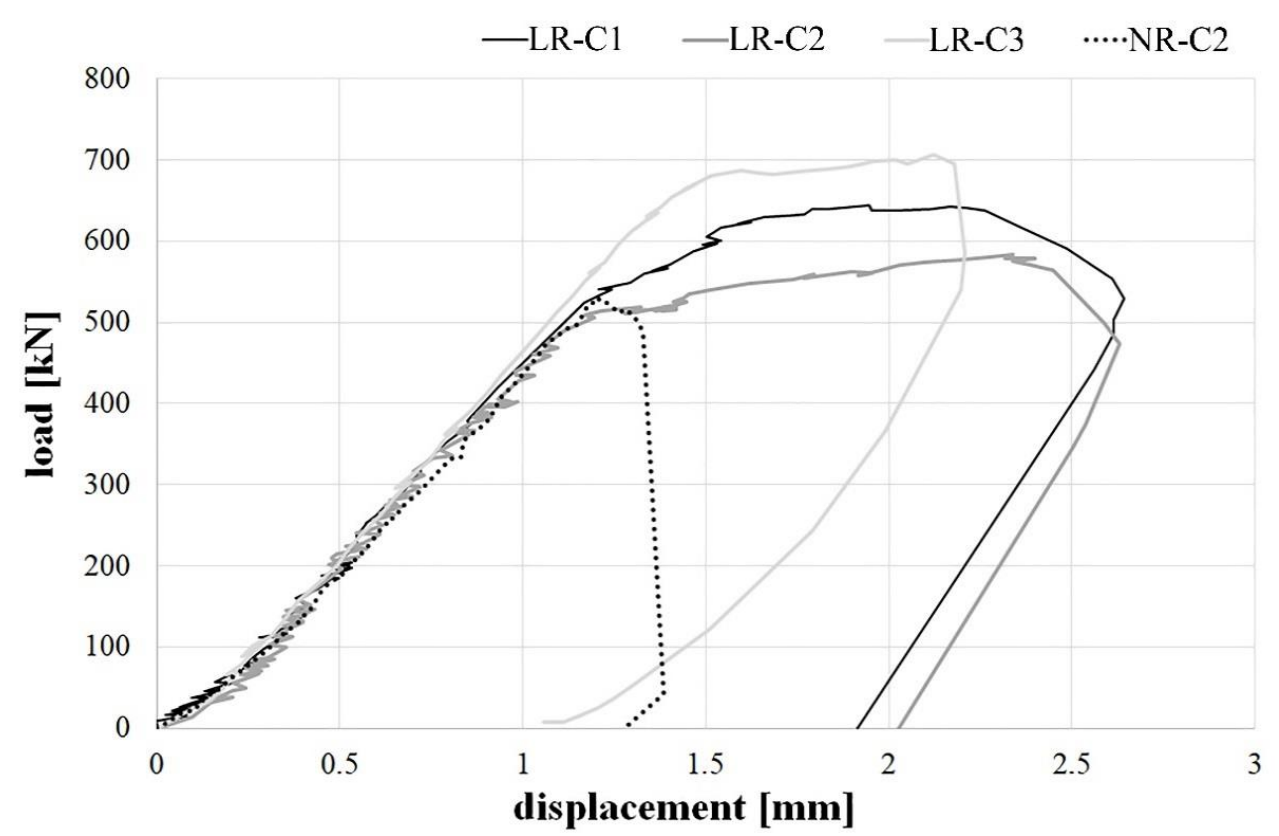

Figure 12. Comparison between the load-displacement diagrams of the three strengthened specimens (continuous curves) and the reference NR-C2 unstrengthened specimen (dotted curve).

The results in Table 5 show the effectiveness of the FRLM composite both in terms of strength and ductility increase, which were $21 \%$ and $66 \%$, respectively, higher than those detected on the unstrengthened columns.

Despite the use of the FRLM composite made of a completely natural lime mortar with low mechanical properties, the experimental results highlighted that it can be successfully used for interventions aimed at increasing the load-bearing capacity and ductility of axially compressed members. Such a composite could be used particularly in the case of historical masonry buildings thanks to the natural mortar used as a matrix and the fully compatibility with the historical substrate.

\section{Discussion}

The effectiveness of the FRLM composite has been analytically assessed using the predictive models described in Section 2. The values of mechanical properties obtained by the tests have been inputted in the analytical formulas. Numerical results have been compared to the experimental ones.

In particular, Equations (3)-(7) demonstrated that they are not able to correctly predict the strength of the confined columns as this was determined in the laboratory tests. In fact, the application of all formulas available in the literature leads to the neglect of any contribution of the FRLM composite wrap in increasing the strength of the masonry confined member. More precisely, all formulas provided a strength value of the confined member basically coincident with that of the unconfined specimen, ranging from 8.52 to 8.55 MPa. The formula in the Italian guidelines CNR-DT 215/2018 [23] estimated only a very minimal increase of strength (about $0.3 \%$ ), so was not relevant if compared to the actual $21 \%$ experimentally obtained. Even if the predictive formulas available in the literature are basically conservative, a similar underestimation leads to an erroneous evaluation of ineffectiveness of such a composite in strengthening masonry columns. Considering that in [34] it has been proved that the available predictive formulas, including the CNR formula, are able to correctly estimate the load-bearing capacity increase of the wrapped columns, the discrepancy between analytical and experimental results obtained in this 
study can be ascribed to the very low mechanical properties of the natural mortar used as the matrix of the FRLM composite with respect to the properties of the mortar used to bond the masonry units of the column which directly influences the final value of the effective confinement pressure (Equation (11)).

It is clear that a fully natural mortar matrix cannot have high mechanical properties, but, as experimentally determined, it can still increase both the strength and ductility of axially compressed members. In particular, the FRLM composite can be very useful-in terms of mechanical and compatibility requirements-for strengthening masonry columns of buildings belonging to historical heritage, and, for this reason, new experimental campaigns are in progress at the Laboratory of the University of Florence in order to evaluate the variation in the prediction capabilities of the existing formulas when the mortar grade is opportunely varied.

\section{Conclusions}

In this paper the effectiveness of FRLM composites for confining masonry square columns was experimentally assessed. Six columns with a full-scale cross-section were built at the Laboratory of Materials and Structures of the University of Florence and tested under axial compression. A natural and compatible lime-based mortar matrix was used to assemble the composite. Despite the use of a natural matrix with very low mechanical properties, strengthened columns highlighted an increase of strength and ductility of $21 \%$ and $66 \%$, respectively. Predictive formulas from the literature and from the Italian guidelines CNR-DT 215/2018 did not perfectly fit the experimental outcomes and did not confirm the strength increase of the confined columns as experimentally obtained.

Considering this, although wider experimental campaigns are needed for more general considerations, it can be concluded that:

- FRLM composites made of a natural matrix with low mechanical properties can be effective for increasing the strength and the ductility of masonry columns-this second aspect is crucial in the case of historical buildings located in seismic areas;

- As a consequence of the previous point, an FRLM composite was shown to be a good strengthening solution in the case of interventions on columns of historical buildings where compatibility between new and original materials is a specific requirement;

- The equations currently present in the literature were demonstrated to be able to fit the experimental outcomes of many researcher's investigations, where mortar used to form the composite had good mechanical properties, largely higher than those of the mortar joints of the column;

- As a result of the present investigation, the same equations present in the literature were not able to correctly predict the effectiveness of the used composite in increasing the strength of the confined columns; this result, probably, depends on the low mechanical properties of mortar which directly influence the formula with respect to confinement pressure;

- A further effort should be made by researchers to take into account the contribution of the composite wrap in terms of ductility increase on confined members, this being a crucial factor in seismic areas.

Author Contributions: All authors contributed in the same way to the research. All authors have read and agreed to the published version of the manuscript.

Funding: This research received no external funding.

Institutional Review Board Statement: Not applicable.

Informed Consent Statement: Not applicable.

Conflicts of Interest: The authors declare no conflict of interest. 


\section{References}

1. Alecci, V.; Ayala, A.; De Stefano, M.; Marra, A.; Nudo, R.; Stipo, G. Influence of the masonry wall thickness on the outcomes of double flat-jack test: Experimental and numerical investigation. Constr. Build. Mater. 2021, 285, 122912. [CrossRef]

2. Alecci, V.; De Stefano, M.; Luciano, R.; Marra, A.M.; Stipo, G. Numerical Investigation on the Use of Flat-Jack Test for Detecting Masonry Deformability. J. Test. Eval. 2020, 49, 537-549. [CrossRef]

3. Giresini, L.; Stochino, F.; Sassu, M. Economic vs environmental isocost and isoperformance curves for the seismic and energy improvement of buildings considering Life Cycle Assessment. Eng. Struct. 2021, 233, 111923. [CrossRef]

4. Beconcini, M.L.; Cioni, P.; Croce, P.; Formichi, P.; Landi, F.; Mochi, C. Non-linear static analysis of masonry buildings under seismic actions. In Proceedings of the 12th International Multi-Conference on Society, Cybernetics and Informatics (IMSCI 2018), Orlando, FL, USA, 8-11 July 2018; Callaos, N., Ed.; International Institute of Informatics and Systemics (IIIS): Orlando, FL, USA, 2020; pp. 126-131.

5. de Falco, A.; Giresini, L.; Sassu, M. Temporary Preventive Seismic Reinforcements on Historic Churches: Numerical Modeling of San Frediano in Pisa. Appl. Mech. Mater. 2013, 351-352, 1393-1396. [CrossRef]

6. Croce, P.; Beconcini, M.L.; Formichi, P.; Cioni, P.; Landi, F.; Mochi, C.; Giuri, R. Influence of mechanical parameters on non-linear static analysis of masonry buildings: A relevant case-study. Procedia Struct. Integr. 2018, 11, 331-338. [CrossRef]

7. Borri, A.; Grazini, A. Masonry columns strengthening with FRP materials. In Proceedings of the 2nd Congress on Mechanics of Masonry Structures Strengthened with FRP-Materials: Modeling, Testing, Design, Control, Venice, Italy; Ceriolo, L., Zerbo, V., Eds.; Cortina Ed.: Padova, Italy, 2004; pp. 193-202.

8. Corradi, M.; Grazini, A.; Borri, A. Confinement of brick masonry columns with CFRP materials. Compos. Sci. Technol. 2007, 67, 1772-1783. [CrossRef]

9. Krevaikas, T.D.; Triantafillou, T. Masonry Confinement with Fiber-Reinforced Polymers. J. Compos. Constr. 2005, 9, 128-135. [CrossRef]

10. Campione, G.; Miraglia, N. Strength and strain capacities of concrete compression members reinforced with FRP. Cem. Concr. Compos. 2003, 25, 31-41. [CrossRef]

11. Mander, J.B.; Priestley, M.J.N.; Park, R. Theoretical Stress-Strain Model for Confined Concrete. J. Struct. Eng. 1988, 114, 1804-1826. [CrossRef]

12. Alecci, V.; Barducci, S.; De Stefano, M.; Galassi, S.; Luciano, R.; Rovero, L.; Stipo, G. Reliability of Different Test Setups and Influence of Mortar Mixture on the Fabric-Reinforced Cementitious Matrix-to-Brick Bond Response. J. Test. Eval. 2021, 49, 4476-4495. [CrossRef]

13. Barducci, S.; Alecci, V.; De Stefano, M.; Misseri, G.; Rovero, L.; Stipo, G. Experimental and Analytical Investigations on Bond Behavior of Basalt-FRCM Systems. J. Compos. Constr. 2020, 24, 04019055. [CrossRef]

14. Minafò, G.; La Mendola, L. Experimental investigation on the effect of mortar grade on the compressive behaviour of FRCM confined masonry columns. Compos. Part B Eng. 2018, 146, 1-12. [CrossRef]

15. Murgo, F.; Mazzotti, C. Masonry columns strengthened with FRCM system: Numerical and experimental evaluation. Constr. Build. Mater. 2019, 202, 208-222. [CrossRef]

16. Cascardi, A.; Micelli, F.; Aiello, M.A. FRCM-confined masonry columns: Experimental investigation on the effect of the inorganic matrix properties. Constr. Build. Mater. 2018, 186, 811-825. [CrossRef]

17. Richart, F.E.; Brandtzaeg, A.; Brown, R.L. The Failure of Plain and Spirally Reinforced Concrete in Compression; Engineering Experimental Station 1929, Bulletin n. 190; University of Illinois: Urbana, IL, USA, 1929; pp. 3-72.

18. Richart, F.E.; Brandtzaeg, A.; Brown, R.L. A Study of the Failure of Concrete under Combined Compressive Stresses; Engineering Experimental Station 1928, Bulletin n. 185; University of Illinois: Urbana, IL, USA, 1928; pp. 3-102.

19. Zampieri, P. Horizontal capacity of single-span masonry bridges with intrados FRCM strengthening. Compos. Struct. 2020, 244, 112238. [CrossRef]

20. Cascardi, A.; Dell'Anna, R.; Micelli, F.; Lionetto, F.; Aiello, M.A.; Maffezzoli, A. Reversible techniques for FRP-confinement of masonry columns. Constr. Build. Mater. 2019, 225, 415-428. [CrossRef]

21. Krevaikas, T.D. Experimental study on carbon fiber textile reinforced mortar system as a means for confinement of masonry columns. Constr. Build. Mater. 2019, 208, 723-733. [CrossRef]

22. Balsamo, A.; Cascardi, A.; Di Ludovico, M.; Aiello, M.A.; Morandini, G. Analytical study on the effectiveness of the FRCMconfinement of masonry columns. In Proceedings of the 7th Euro-American Congress on Construction Pathology, Rehabilitation Technology and Heritage Management (Rehabend 2018), Càceres, Spain, 15-18 May 2018; pp. 1-9.

23. CNR-DT 215/2018. Istruzioni per la Progettazione, l'Esecuzione ed il Controllo di Interventi di Consolidamento Statico Mediante L'utilizzo di Compositi Fibrorinforzati a Matrice Inorganica; Commissione di Studio per la Predisposizione e L'analisi di Norme Tecniche Relative Alle Costruzioni: Roma, Italy, 2018.

24. UNI EN 772-1. Metodi di Prova per Elementi per Muratura-Parte 1: Determinazione della Resistenza a Compressione; Ente Nazionale Italiano di Unificazione (European Committee for Standardization): Milan, Italy, 2015.

25. UNI EN 1015-11. Metodi di Prova per Malte per Opere Murarie-Determinazione della Resistenza a Flessione e a Compressione della malta Indurita; Ente Nazionale Italiano di Unificazione (European Committee for Standardization): Milan, Italy, 2007.

26. Arboleda, D.; Carozzi, F.G.; Nanni, A.; Poggi, C. Testing Procedures for the Uniaxial Tensile Characterization of Fabric-Reinforced Cementitious Matrix Composites. J. Compos. Constr. 2016, 20, 04015063. [CrossRef] 
27. De Santis, S.; Hadad, H.A.; Basalo, F.D.C.Y.; De Felice, G.; Nanni, A. Acceptance Criteria for Tensile Characterization of FabricReinforced Cementitious Matrix Systems for Concrete and Masonry Repair. J. Compos. Constr. 2018, 22, 04018048. [CrossRef]

28. Bernat-Maso, E.; Gil, L.; Mercedes, L.; Escrig, C. Mechanical properties of pre-stressed fabric-reinforced cementitious matrix composite (PFRCM). Constr. Build. Mater. 2018, 191, 228-241. [CrossRef]

29. Focacci, F.; D'Antino, T.; Carloni, C. The role of the fiber-matrix interfacial properties on the tensile behavior of FRCM coupons. Constr. Build. Mater. 2020, 265, 120263. [CrossRef]

30. Lignola, G.P.; Caggegi, C.; Ceroni, F.; De Santis, S.; Krajewski, P.; Lourenço, P.B.; Morganti, M.; Papanicolaou, C.; Pellegrino, C.; Prota, A.; et al. Performance assessment of basalt FRCM for retrofit applications on masonry. Compos. Part B Eng. 2017, 128, 1-18. [CrossRef]

31. Carozzi, F.G.; Bellini, A.; D’Antino, T.; De Felice, G.; Focacci, F.; Hojdys, Ł.; Laghi, L.; Lanoye, E.; Micelli, F.; Panizza, M.; et al. Experimental investigation of tensile and bond properties of Carbon-FRCM composites for strengthening masonry elements. Compos. Part B Eng. 2017, 128, 100-119. [CrossRef]

32. Sneed, L.H.; Baietti, G.; Fraioli, G.; Carloni, C. Compressive Behavior of Brick Masonry Columns Confined with Steel-Reinforced Grout Jackets. J. Compos. Constr. 2019, 23, 04019037. [CrossRef]

33. Alecci, V.; Focacci, F.; Rovero, L.; Stipo, G.; De Stefano, M. Extrados strengthening of brick masonry arches with PBO-FRCM composites: Experimental and analytical investigations. Compos. Struct. 2016, 149, 184-196. [CrossRef]

34. Aiello, M.; Bencardino, F.; Cascardi, A.; D’Antino, T.; Fagone, M.; Frana, I.; La Mendola, L.; Lignola, G.; Mazzotti, C.; Micelli, F.; et al. Masonry columns confined with fabric reinforced cementitious matrix (FRCM) systems: A round robin test. Constr. Build. Mater. 2021, 298, 123816. [CrossRef] 